\title{
Effect of Paper Mulberry Extract on Damaged Hair
}

Ju-Sub Kim

Department of Beauty Design, Sangji University, Wonju-si, Gangwon-do, Korea

Corresponding author: Ju-Sub Kim, Department of Beauty Design, Sangji University, 84 Sangjidae-gil, Wonju-si, Gangwondo 26339, Korea

Tel.: +82 337300811

Fax: +82337300811

Email: c-miro@hanmail.net

Received March 17, 2021

Revised April 13, 2021

Accepted April 14, 2021

Published June 30, 2021

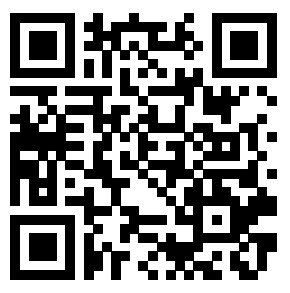

\begin{abstract}
Purpose: The study aims to manufacture paper mulberry-added formulations to improve hair quality, apply it to damaged hair, and examine the effect of the formulations in improving hair quality. Methods: Formulations were manufactured by varying the contents of paper mulberry extract at $0,2,4$, and $6 \mathrm{~g}$. Then, the formulations were applied to discolored sample hairs, which were treated with heat and left in nature. Then, the conditions of the sample hairs before and after application of the formulations were compared. To examine the effect of the formulations on hair quality, the study measured tensile strength, optical absorption using methylene blue, and luster. Results: For all samples, the average values for tensile strength increased after application of the formulations, especially for samples $7 \mathrm{~L}(1), 7 \mathrm{~L}(2), 7 \mathrm{~L}(3)$, and $9 \mathrm{~L}(3)$. The analysis of optical absorption using methylene blue demonstrated that the average values for optical absorption decreased for all samples except in the case of healthy hair. Such decreases were noted for samples $7 \mathrm{~L}(1), 7 \mathrm{~L}(2), 7 \mathrm{~L}(3)$, and $9 \mathrm{~L}(3)$. Finally, the average values for luster increased samples $7 \mathrm{~L}(3)$ and $9 \mathrm{~L}(3)$. Conclusion: The study found that paper mulberry extract is effective for improving tensile strength, optical absorption, and luster of damaged hair. However, the study only verified the results on a limited number of hair characteristics and used one ingredient. Thus, further research using various measurement methods and other ingredients is necessary.
\end{abstract}

Keywords: Paper mulberry, Hair, Improvement, Hair texture, Damage

\section{Introduction}

경제적인 성장과 더불어 아름다움을 추구하고자 하는 욕구로 인해 미용산업은 많은 성장을 하였다(Park et al., 2019). 미용산업의 발 달로 인해 헤어 디자인 연출에 필요한 모발화장품 제품들도 발달하 였다. 헤어디자인 연출 시 필요한 모발화장품 제품에는 헤어컬러 변 화를 주고자 할 때 필요한 염모제와 탈색제, 영구적인 웨이브를 연 출하고자 할 때 필요한 퍼머넌트제가 대표적이다(Park \& Kwack, 2018). 이러한 모발화장품은 헤어디자인 변화를 주어 헤어 스타일을 아름답게 표현하기도 하지만 그에 따른 모발손상도 같이 이루어 진 다. 화학적인 손상으로 인해 모발은 모표피 박리와 일부 성분의 유실 에 의해 모발의 물리적 성질이 변화한다. 변화로는 모발의 질변화, 다공성모, 탄력의 변화 등이 생긴다(Kim et al., 2010). 손상된 모발 은 다시 원상태로 회복이 되지 않고 샴푸, 브러싱 등에 의해 손상이 악화가 된다. 모발이 다공성모가 되어 탄력 감소하고, 모표피 박리로 인해 부스러지기도 하며, 윤기도 감소를 한다(Cha, 2013). 모발 손
상을 방지하기 위한 방법으로 가장 좋은 방법은 화학적 처리를 하지 않는 것이지만 현실적으로 헤어컬러 변화, 직모를 웨이브로 변화 할 시 불가피하게 화학적 성분이 첨가된 제품을 사용할 수 밖에 없다. 손상된 모발을 원상태로 돌릴 수는 없지만 더 이상 손상이 악화되 지 않도록 하는 모발의 질 개선을 위한 헤어 트리트먼트제 개발과 성 분 연구가 활발히 이루어 지고 있다. 손상된 모발의 개선을 위한 연 구로는 숭어추출물이 염색과 탈색 모발의 물리적 손상에 미치는 영 향(Min et al., 2011), 국화산 추출물에 의한 화학적 손상 모발의 물 리학적 변화(Lee \& Cho, 2018), 인삼추출물을 처방한 환원제 적용 에 따른 모발 손상도 및 형태적 변화(Lee \& Ham, 2010) 등이 있다. 이렇게 모발의 질 개선을 위한 다양한 연구가 이루어지고 있으나 성 분 연구에 따른 연구 등의 연구가 더욱 필요하다. 이에 성분에 관한 연구로 추출물을 사용하여 모발의 질 개선 효과를 알아보고자 하였 다. 다양한 추출물 중에 닥나무에서 추출한 오일을 사용하여 모발의 질 개선 효과를 연구하고자 하였다. 닥나무는 뽕나무과로 한국, 대만 
과 일본에 널리 자생하고 있는 낙엽활엽관으로 주로 낮은 산지에서 자생한다. 동의보감에 닥나무의 과실은 저수피라하여 요통이나 부종 치료에 사용되며, 전통한지를 만드는 주재료로 알려져 있으며 미백 효과가 있는 것으로 보고되어 있다(Park et al., 2013), 또한 닥나무 추출물은 보습효과도 있어 그 보습효과가 손상된 모발의 질 개선에 도움이 될 것으로 사료되어 연구에 사용하게 되었다. 닥나무에 관한 연구로는 닥나무 뿌리 추출물을 함유하는 고분자 마이크로입자 제조 및 평가(Lim et al., 2013), 닥나무를 이용한 천연 비누 개발과 효과 분석에 관한 연구(Baek et al., 2008), 삼백초, 뽕나무 줄기, 닥나무 줄기 등을 함유한 복합수목추출물의 화장품 소재 특성(Jeong et al., 2012) 등이 있다. 화장품 관련한 연구는 있으나 모발화장품 관련한 연구는 없는 실정이다.

본 연구는 닥나무 추출물이 모발의 질 개선 원료로 효과가 있는지 를 알아보고자 하였다. 효과 검증을 위해 추출물을 함량 별로 다르게 하여 사용하였다. 도포 시 모발에 추출물의 흡착력을 높이기 위해 펌 베이스제에 첨가하여 제조하였다. 제조된 제형으로 모발에 도포 전, 후의 모발의 질 개선 정도를 비교 분석하였다. 모발의 질 개선 효과 가 있는지 알기 위해 인장강도 측정, 메틸렌블루를 이용한 흡광도 측 정과 광택을 측정하여 비교 분석하였다.

\section{Methods}

\section{1. 실험재료}

1) 시료 모발

실험에 사용된 모발은 최근 2 년 동안 약물복용과 화학적 시술 을 하지 않은 여성의 모발을 후두부에서 두피 로부터 $3 \mathrm{~cm}$ 지점을 기준으로 $20 \mathrm{~cm}$ 로 채취하여 $3 \mathrm{~g}$ 씩 모(hair) 다발을 만들었다. 플 레인 린스 후 자연건조하여 사용하였다. 닥나무 추출물에 의한 모
발의 질 개선 변화를 연구하기 위하여 화학적시술을 전혀 하지 않 은 건강모와 건강 모발에 탈색제 제1제(ammonium persulfate, potassium persulfate, sodium metasilicate, magnesium, sodium carboxymethyl cellulose) (Suanhj, Korea) $20 \mathrm{mg}$ 과 제2제(6\%의 과산화수소를 주성분으로 water, etidronic acid, phosphoric acid, sodium phosphate dibasic, cetyl alcohol로 구성된 제품) (Suanhj, Korea) $20 \mathrm{~mL}$ 를 1:1 비율로 혼합, 도포하고 $30 \mathrm{~min}$ 방치 후 세척하 여 명도 7레벨 시료 4 다발과 명도 차에 의한 비교를 위해 한번의 탈 색을 더해서 9 레벨의 시료 1 다발을 제작하였다. 실험에 사용된 모 발 시료의 level 측정기(level scale, Wella, Germany) 사용하여 측정 하였다. 이 시료에 닥나무 추출물을 중탕하여 모발 시료에 도포 전과 후를 비교하였다.

\section{2) 닥나무 추출물}

실험에 사용 한 닥나무 추출물은 원산지는 한국이고 추출은 뿌리 에서 추출한 추출물로 화장품원료로 사용되는 오일로 코리아밀락 (Korea Similac, Walterenterprise Co., Korea)에서 구입하여 사용하 였다.

3) 닥나무 추출물 첨가 제형제 제조

도포를 위해 실험에 사용한 모질 개선 제형제의 펌베이스제는 (주) 수안향장(Korea)에서 제조한 것을 사용하였으며, 펌베이스제 조성표 는 Table 1 과 같다.

4) 측정기기 및 측정방법

(1) 인장강도 측정

모발의 질 개선 정도를 알기 위해 모발 시료에 도포 전과 후의 인장 강도를 측정하였다. 측정 기기(digital force gauge, HF-20; Tripod, China)로 인장강도를 측정하였다. 측정값의 신뢰성을 위하여 12 회 측

Table 1. Composition of perm-base agent

\begin{tabular}{|c|c|c|c|}
\hline No & Ingredients & Content (\%) & Function \\
\hline 1 & Water & 89.850 & Solvent \\
\hline 2 & Triethanolamine & 0.150 & PH adjuster \\
\hline \multirow{2}{*}{3} & Cetyl alcohol & \multirow{2}{*}{3.000} & Emulsion stabilizer \\
\hline & Ceteth-40 & & Surfactant \\
\hline \multirow{4}{*}{4} & Myristyl alcohol & \multirow{4}{*}{2.000} & Emulsion stabilizer \\
\hline & Cetyl alcohol & & Emulsion stabilizer \\
\hline & Stearyl alcohol & & Emulsion stabilizer \\
\hline & Arachidyl alcohol & & Emulsion stabilizer \\
\hline \multirow{3}{*}{5} & Stearic acid & \multirow{3}{*}{1.000} & Surfactant \\
\hline & Palmitic acid & & Surfactant \\
\hline & Myristic acid & & Surfactant \\
\hline 6 & Mineral oil & 4.000 & Conditioning agent \\
\hline
\end{tabular}


정 후 최고 값과 최저 값을 제외한 값으로 통계분석 하였다.

\section{(2) 메틸렌블루를 이용한 흡광도 측정}

모발의 질 개선 정도를 알기 위해 모발 시료에 도포 전과 후의 흡 광도를 메틸렌블루(methylene blue, $\mathrm{MB}$ )를 이용하여 측정하였다. 모발의 굵기 측정기기로는 마이크로미터(Quickmike, Mitutoyo)를 이용하여 0.070-0.075 mm의 굵기 오차범위를 정하고 $4 \mathrm{~cm}$ 의 길 이 잘랐다. 자른 모발을 tube에 넣은 후 MB solution에 담가 vortex mixer (Vortex genie 2, Scientific Industries, USA)를 이용하여 10 $\mathrm{s}$ 동안 vortexing하였다. $50^{\circ} \mathrm{C}$ heat block (wise therm $\mathrm{HB}-48 \mathrm{P}$; Daihan Scientific, Korea)에서 $10 \mathrm{~min}$ 간 유지하여 MB solution을 흡착시키고, tube에 있는 2 가닥의 시료를 꺼내어 표면에 묻어있는 $\mathrm{MB}$ solution은 실험용 티슈를 이용하여 제거하고, 시료 2 가닥을 각 각 새 tube에 옮겨 담았다. 이 tube에 NR desorb solution을 $5 \mathrm{~mL}$ 를 넣고 상온에서 $5 \mathrm{~min}$ 방치 후 $10 \mathrm{~s}$ vortexing 후 추출하였다. 추 출한 용액을 큐벳(cuvettes)에 $3000 \mu \mathrm{L}$ 분주하여 $\mathrm{MB}$ 의 흡수 강도가 가장 높은 파장인 $660 \mathrm{~nm}$ 로 흡광도를 측정하였다. 모다발 별로 2 가 닥씩 같은 방법으로 2 번 측정하여 통계 분석하였다. 측정 시 기준 값 을 잡기 위해 desorb solution을 $3000 \mu \mathrm{L}$ 분주하여 blank를 만들어 준다. $\mathrm{MB}$ 시약은 $\mathrm{DW} 20 \mathrm{~mL}+\mathrm{MB} 400 \mu \mathrm{L}$ 으로 희석하여 $2 \%$ 로 만 들어 사용하였다. NR solution은 $49 \%$ ethanol $(49 \mathrm{~mL})+1 \%$ glacial aceticacid $(1 \mathrm{~mL})+50 \% \mathrm{DW}(50 \mathrm{~mL})$ 의 비율로 완성하였다.

\section{(3) 모발 표면 광택 측정}

모발의 질 개선 정도를 알기 위해 모발 시료에 도포 전과 후의 광 택 변화를 측정하였다. 측정기기는 광택계(Gloss meter NHG268; Shenzhen Threenh Technology, China)를 이용하여 측정하였다. 측 정값의 신뢰성을 높이기 위해 12 번 측정 후 최고값과 최저값을 제외 한 값으로 jamovi 1.2.27 solid (University of Newcastle, Australia) 를 이용하여 $t$-tests 통계분석 하였다.

\section{5) 도포 실험방법}

건강모와 탈색으로 시술 한 모발 시료 7레벨, 9 레벨 시료에 $15 \mathrm{~g}$ 도포하였다. 도포 후 열처리 $10 \mathrm{~min}$ 후 자연방치 $20 \mathrm{~min}$ 방치 후에 세척하여 자연건조 시켜 측정하였다. 도포는 도포량, 자연방치시간,
열처리 시간, 시술자의 숙련도에 등에 따라서 측정과 결과에 차이가 있을 수 있기 때문에 최대한 차이를 줄이기 위해 시술자는 각 단계별 로 동일인이 시술하였다. 각 레벨과 따른 시료 표기는 Table 2 와 같 다. $7 \mathrm{~L}(0)$ 은 7레벨 모다발에 닥나무추출물 $0 \mathrm{~g}$ 에 펌베이스 $20 \mathrm{~g}$ 을 혼합, $7 \mathrm{~L}(1)$ 은 모다발에 닥나무추출물 $2 \mathrm{~g}$ 에 펌베이스 $18 \mathrm{~g}$ 을 혼합, $7 \mathrm{~L}(2)$ 은 모다발에 닥나무추출물 $4 \mathrm{~g}$ 에 펌베이스 $16 \mathrm{~g}$ 을 혼합, $7 \mathrm{~L}(3)$ 은 모다발에 닥나무추출물 $6 \mathrm{~g}$ 에 펌베이스 $14 \mathrm{~g}$ 을 혼합, $9 \mathrm{~L}(1)$ 은 9 레 벨 모다발에 닥나무추출물 $6 \mathrm{~g}$ 에 펌베이스 $14 \mathrm{~g}$ 을 혼합한 것이다.

\section{6) 결과 분석}

각 항목의 실험은 실험에 따라 인장강도와 광택은 12 회 측정, 흡 광도는 4회 측정한 값을 도포 전과 후를 비교하였다. 신뢰성과 객관 성을 높이기 위한 통계분석을 위해 평균(mean), 표준편차(standard division, $\mathrm{SD}$ )를 구하고 사후 검증으로 통계 프로그램인 jamovi 1.2.27 solid를 이용하여 $t$-tests (Paired sample $t$-test)로 양측검정 (two tailed test)실시하였고, 유의 수준은 $p<0.05$ 수준에서 검증하였 다. 귀무가설은 "도포 전과 후의 차이가 없다" 이고 연구가설은 "도포 전과 후의 차이가 있다"로 하였다.

\section{Results and Discussion}

\section{1. 시료 별의 인장강도 측정}

닥나무 추출물을 첨가하여 제조한 제형제로 시료에 도포 전, 후 인 장강도 측정 결과는 Table 3 과 같다. 도포 전 같은 7 레벨의 인장강도 값이 차이가 나는 것은 모다발 별로 모질의 차이에 의한 것이다. 시 료별로 평균의 차이가 표본을 추출 할 때 발생하는 표본 오차에 의한 차이인지 아니면 모평균 차이에 의한 것이지 판단하기 위해 모든 시 료에 대응표본 $t$-검정을 통해 검정하였다. 건강모 시료의 도포 전과 후 평균 값은 0.13 차이를 보였다. 유의확률( $p$-value) 0.256 로 유의 기준 $p<0.05$ 보다 큰 값으로 유의미하지 않음을 알 수 있었다. 이는 연구가설이 기각되어 건강모에서는 인장강도 변화가 없는 것을 알 수 있었다. $7 \mathrm{~L}(0)$ 시료의 도포전과 후의 평균 값 차이는 0.07 차이를 보였 다. 유의확률은 0.527 로 유의기준 $p<0.05$ 보다 큰 값으로 유의미하 지 않음을 알 수 있어 인장강도의 변화는 없음을 알 수 있었다. $7 \mathrm{~L}(1)$

\section{Table 2. Expression method for samples}

\begin{tabular}{ll}
\hline Sample & Treatment of undamaged hair with $6 \mathrm{~g}$ of paper mulberry extract and $14 \mathrm{~g}$ of perm-base agent \\
Virgin hair & Treatment of level- 7 sample with $0 \mathrm{~g}$ of paper mulberry extract and $20 \mathrm{~g}$ of perm-base agent \\
$7 \mathrm{~L}(0)$ & Treatment of level-7 sample with $2 \mathrm{~g}$ of paper mulberry extract and $18 \mathrm{~g}$ of perm-base agent \\
$7 \mathrm{~L}(2)$ & Treatment of level-7 sample with $4 \mathrm{~g}$ of paper mulberry extract and $16 \mathrm{~g}$ of perm-base agent \\
$7 \mathrm{~L}(3)$ & Treatment of level-7 sample with $6 \mathrm{~g}$ of paper mulberry extract and $14 \mathrm{~g}$ of perm-base agent \\
$9 \mathrm{~L}(3)$ & Treatment of level-9 sample with $6 \mathrm{~g}$ paper mulberry extract and $14 \mathrm{~g}$ of perm-base agent \\
\hline
\end{tabular}


시료에 도포 전과 후의 평균값은 0.16 차이를 보였다. 검정결과 유의 확률이 0.022 로 유의기준 $p<0.05$ 보다 작은 값으로 유의미한 결과를 알 수 있어 인장강도 변화가 있는 것을 알 수 있었다. $7 \mathrm{~L}(2)$ 시료에 도 포 전과 후의 평균값은 차이는 0.05 차이를 나타낸다. 검정결과 유의 확률이 0.022 로 유의기준 $p<0.05$ 보다 값으로 유의미한 결과를 알 수 있어 인장강도 변화가 있는 것을 알 수 있었다. $7 \mathrm{~L}(3)$ 시료에 도포 전과 후의 평균값은 0.17 차이를 보였다. 검정결과 유의확률이 0.031 로 유의기준 $p<0.05$ 보다 작은 값으로 유의미 한 결과를 알 수 있어 인장강도 변화가 있는 것을 알 수 있었다. $9 \mathrm{~L}(3)$ 시료에 도포 전과 후 의 평균값은 0.28 차이를 보였다. 검정결과 유의확률이 0.001 로 유 의기준 $p<0.05$ 보다 작은 값으로 유의미한 결과를 알 수 있어 인장강 도 변화가 있는 것을 알 수 있었다. 이는 귀무가설이 기각되고 영구 가설 "도포 전과 후의 차이가 있다"가 채택되어 통계분석 결과 닥나무 추출물을 첨가한 시료에서 인장강도가 증가한 것을 알 수 있었다. 인 장강도가 증가하여 모발의 질 개선에 효과가 있는 을 알 수 있었다. 이는 서리태 발효 추출물을 첨가한 모발이 탈색 모발 보다 인장강도 가 가하고(Jung et al., 2017), 밍크 오일을 첨가 시 인장강도가 증가 한다(Kim, 2020)는 결과와 같은 것을 알 수 있었다.

\section{2. 시료 별의 메틸렌블루를 이용한 흡광도 측정}

닥나무 추출물을 첨가하여 제조한 제형제로 시료에 도포 전·후 흡 광도 측정 결과는 Table 4 와 같다. 도포 전 같은 7 레벨의 흡광도 값
이 차이가 나는 것은 모다발 별로 모질의 차이에 의한 것이다. 시료별 로 평균의 차이가 표본을 추출 할 때 발생하는 표본 오차에 의한 차이 인지 아니면 모평균 차이에 의한 것이지 판단하기 위해 모든 시료에 대응표본 $t$-검정을 통해 검정하였다. 건강모 시료에 도포 전과 후 평 균값은 0.003 차이를 보였다. 유의확률( $p$-value) 0.766 으로 유의기 준 $p<0.05$ 보다 큰 값으로 유의하지 않음을 알 수 있었다. 이는 연구 가설이 기각되어 건강모에서는 흡광도 변화가 없는 것을 알 수 있었 다. $7 \mathrm{~L}(0)$ 시료의 도포전과 후의 평균 값 차이는 0.052 차이를 보였다. 유의확률은 0.097 로 유의기준 $p<0.05$ 보다 큰 값으로 유의미하지 않 음을 알 수 있어 흡광도 변화가 없는 것을 알 수 있었다. $7 \mathrm{~L}(1)$ 시료에 도포 전과 후의 평균값은 0.054 차이를 나타낸다. 검정결과 유의확률 이 0.001 로 유의기준 $p<0.05$ 보다 작은 값으로 유의미한 결과를 알 수 있어 흡광도 변화가 있는 것을 알 수 있었다. $7 \mathrm{~L}(2)$ 시료에 도포 전 과 후의 평균값은 0.109 차이를 보였다. 검정결과 유의확률이 0.001 로 유의기준 $p<0.05$ 보다 작은 값으로 유의미한 결과를 알 수 있어 흡 광도 변화가 있는 것을 알 수 있었다. $7 \mathrm{~L}(3)$ 시료에 도포 전과 후의 평 균값은 0.139 차이를 보였다. 검정결과 유의확률이 0.003 로 유의기준 $p<0.05$ 보다 작은 값으로 유의미한 결과를 알 수 있어 흡광도 변화가 있는 것을 알 수 있었다. $9 \mathrm{~L}(3)$ 시료에 도포 전과 후의 평균값은 0.134 차이를 보였다. 검정결과 유의확률이 0.001 로 유의기준 $p<0.05$ 보다 작은 값으로 유의미한 결과를 알 수 있어 흡광도 변화가 있는 것을 알 수 있었다. 통계분석 결과 시료 $7 \mathrm{~L}(1), 7 \mathrm{~L}(2), 7 \mathrm{~L}(3), 9 \mathrm{~L}(3)$ 모두 유의

Table 3. Statistical analysis of tensile strength results

(Unit: N)

\begin{tabular}{lcccc}
\hline \multirow{2}{*}{ Sample } & Pre & Post & Statistic & $p$ \\
\cline { 2 - 3 } Virgin hair & Mean \pm SD & Mean $\pm S D$ & -1.21 & 0.256 \\
$7 L(0)$ & $1.24 \pm 0.23$ & $1.37 \pm 0.18$ & -0.65 & 0.527 \\
$7 L(1)$ & $1.02 \pm 0.14$ & $1.09 \pm 0.32$ & -2.27 & $0.022^{*}$ \\
$7 L(2)$ & $0.96 \pm 0.11$ & $1.12 \pm 0.18$ & -2.76 & $0.022^{*}$ \\
$7 L(3)$ & $1.04 \pm 0.13$ & $1.09 \pm 0.11$ & -2.56 & $0.031^{*}$ \\
$9 L(3)$ & $1.04 \pm 0.14$ & $1.21 \pm 0.20$ & -9.09 & $0.001^{*}$ \\
\hline
\end{tabular}

${ }^{*} p<0.05$.

Table 4. Statistical analysis of optical density results

(Unit: Abs)

\begin{tabular}{lcccc}
\hline \multirow{2}{*}{ Sample } & Pre & Post & Statistic & $p$ \\
\cline { 2 - 3 } Virgin hair & Mean \pm SD & Mean \pm SD & -0.38 & 0.766 \\
$7 L(0)$ & $0.073 \pm 0.01$ & $0.076 \pm 0.00$ & 6.50 & 0.097 \\
$7 L(1)$ & $0.263 \pm 0.00$ & $0.211 \pm 0.01$ & 17.20 & $0.001^{*}$ \\
$7 L(2)$ & $0.292 \pm 0.00$ & $0.238 \pm 0.01$ & 13.40 & $0.001^{*}$ \\
$7 L(3)$ & $0.321 \pm 0.01$ & $0.212 \pm 0.00$ & 9.26 & $0.003^{*}$ \\
$9 L(3)$ & $0.361 \pm 0.00$ & $0.222 \pm 0.01$ & 5.40 & $0.012^{*}$ \\
\hline
\end{tabular}

${ }^{*} p<0.05$. 
기준이 $p<0.05$ 보다 작은 값으로 닥나무 추출물에 의해 흡광도 변화 가 있는 것을 알 수 있었다. 같은 7레벨 시료에서는 추출물 함량이 높 을수록 흡광도 차이는 큰 것을 알 수 있었고, 이는 귀무가설이 기각되 고 연구가설 "도포 전과 후의 차이가 있다"가 채택 되어 통계분석결과 흡광도 값이 감소 하는 것을 알 수 있어 모발의 질 개선에 효과가 있 는 것을 알 수 있었다. 이는 땅콩오일의 함량이 증가 할수록 흡광도가 감소하고 $(\mathrm{Kim}, 2020)$, 흡광도가 높을수록 손상도가 높다(Lim, 2018) 는 결과와 반대의 결과임을 알 수 있었다.

\section{3. 시료 별의 광택 측정}

닥나무 추출물을 첨가하여 제조한 제형제로 시료에 도포 전·후 광 택 측정 결과는 Table 5 와 같다. 도포 전 같은 7 레벨의 광택 값이 차 이가 나는 것은 모다발 별로 모질의 차이에 의한 것이다. 시료별로 평 균의 차이가 표본을 추출 할 때 발생하는 표본 오차에 의한 차이인지 아니면 모평균 차이에 의한 것이지 판단하기 위해 모든 시료에 대응 표본 $t$-검정을 통해 검정하였다. 건강모 시료에 도포 전과 후 평균 값 은 0.01차이를 보였다. 유의확률( $p$-value) 0.591 로 유의기준 $p<0.05$ 보다 큰 값으로 유의하지 않음을 알 수 있었다. 이는 연구가설이 기 각되어 건강모에서는 광택 변화가 없는 것을 알 수 있었다. $7 \mathrm{~L}(0)$ 시 료의 도포전과 후의 평균 값 차이는 0.12 차이를 보였다. 유의확률은 0.193 으로 유의기준 $p<0.05$ 보다 큰 값으로 유의미하지 않음을 알 수 있어 광택 변화가 없는 것을 알 수 있었다. $7 \mathrm{~L}(1)$ 시료에 도포 전과 후 의 평균값은 0.01 차이를 보였다. 검정결과 유의확률이 0.758 로 유의 기준 $p<0.05$ 보다 큰 값으로 유의하지 않음을 알 수 있어 광택 변화는 없는 것을 알 수 있었다. $7 \mathrm{~L}(2)$ 시료에 도포 전과 후의 평균값은 0.03 차이를 보였다. 검정결과 유의확률이 0.081 로 유의기준 $p<0.05$ 보다 큰 값으로 유의하지 않음을 알 수 있어 광택 변화는 없는 것을 알 수 있었다. $7 \mathrm{~L}(3)$ 시료에 도포 전과 후의 평균값은 0.06 차이를 보였. 검 정결과 유의확률이 0.024 로 유의기준 $p<0.05$ 보다 작은 값으로 유의 미한 결과를 알 수 있어 광택 변화가 있는 것을 알 수 있었다. 9L(3) 시료에 도포 전과 후의 평균값은 0.36 차이를 보였다. 검정결과 유의 확률이 0.001 로 유의기준 $p<0.05$ 보다 작은 값으로 유의미한 결과
를 알 수 광택 변화가 있는 것을 알 수 있었다. 통계분석결과는 7L(3), $9 \mathrm{~L}(3)$ 시료에서 유의기준이 $p<0.05$ 보다 작은 값으로 이는 귀무가설 이 기각되고 연구가설 "도포 전과 후의 차이가 있다"가 채택되어 통계 결과 닥나무 추출물에 의해 광택 변화가 있는 것을 알 수 있었다. 닥 나무 추출물 함량이 $6 \mathrm{~g}$ 으로 제일 많이 첨가했을 때에만 광택이 증가 하였다.

\section{Conclusion}

닥나무 추출물을 첨가하여 제조한 제형제로 손상 된 모발에 도포 전과 후의 모발 상태를 측정하여 비교 분석 연구하였다. 모발의 질 개선 정도를 알기 위해서 인장강도, 메틸렌블루를 이용한 흡광도, 광 태 측정을 하였다. 그 결과 다음과 같은 결론을 얻었다.

첫째, 인장강도 측정 결과 건강모를 포함한 $7 \mathrm{~L}(0), 7 \mathrm{~L}(1), 7 \mathrm{~L}(2)$, $7 \mathrm{~L}(3), 9 \mathrm{~L}(3)$ 의 평균값이 증가하는 것을 알 수 있었으나, 통계분석으 로는 건강모와 $7 \mathrm{~L}(0)$ 를 제외한 $7 \mathrm{~L}(1), 7 \mathrm{~L}(2), 7 \mathrm{~L}(3), 9 \mathrm{~L}(3)$ 의 시료에 서 인장강도가 증가하는 것을 알 수 있어 모발의 질 개선에 효과가 있 는 것을 알 수 있었다.

둘째, 흡광도 측정 결과 건강모를 제외한 모든 시료에서 평균값이 감소하는 것을 알 수 있었다. 통계분석으로는 건강모와 $7 \mathrm{~L}(0)$ 을 제외 한 7L(1), 7L(2), 7L(3), 9L(3)의 시료에서 감소하는 것을 알 수 있어 모발의 질 개선에 효과가 있는 것을 알 수 있었다.

셋째, 광택 측정 결과 모든 시료에서 평균값은 증가하는 것을 알 수 있었다. 통계분석으로는 닥나무 추출물 $6 \mathrm{~g}$ 첨가한 $7 \mathrm{~L}(3), 9 \mathrm{~L}(3)$ 의 시료에서 증가하였다.

이와 같은 결과로 닥나무 추출물로 모발에 도포 시에 흡광도와 인 장강도, 광택에 변화를 주는 것을 알 수 있어 모발의 질 개선제로 사 용 가능 함을 알 수 있었다. 모발 손상을 줄이기 위한 성분 연구가 이 루어지고 있다. 그러나 개선 효과 측정 방법과 모발의 질을 개선하는 성분에 관한 연구는 부족한 실정이다. 차후 연구 시 효과 측정을 위 해 다양한 측정 방법과 처리에 대한 방법, 성분 연구가 필요하다.

Table 5. Statistical analysis of gloss meter results

\begin{tabular}{lcccc}
\hline \multirow{2}{*}{ Sample } & Pre & Post & Statistic & $p$ \\
\cline { 2 - 3 } Virgin hair & Mean \pm SD & Mean \pm SD & & 0.591 \\
$7 \mathrm{~L}(0)$ & $0.59 \pm 0.03$ & $0.60 \pm 0.04$ & -0.557 & 0.193 \\
$7 \mathrm{~L}(1)$ & $0.97 \pm 0.04$ & $1.09 \pm 0.08$ & -3.670 & 0.758 \\
$7 \mathrm{~L}(2)$ & $0.96 \pm 0.05$ & $0.97 \pm 0.06$ & -0.318 & 0.081 \\
$7 \mathrm{~L}(3)$ & $0.96 \pm 0.05$ & $0.99 \pm 0.05$ & -1.960 & $0.024^{*}$ \\
$9 \mathrm{~L}(3)$ & $0.96 \pm 0.05$ & $1.02 \pm 0.06$ & -2.710 & -16.300 \\
\hline
\end{tabular}

${ }^{*} p<0.05$. 


\section{Author's contribution}

JSK designed all experimental investigations, collected paper mulberry data, and wrote the manuscript.

\section{Author details}

Ju-Sub Kim (Professor), Department of Beauty Design, Sangji University, 84 Sangjidae-gil, Wonju-si, Gangwondo 26339, Korea.

\section{References}

Baek HJ, Lee YR, Jeon KH. A study on the development and effect analysis of natural soaps manufactured with the paper mulberry material. The Journal of the Korea Association Art \& Design, 11: 1-20, 2008.

$\mathrm{Cha} \mathrm{OH}$. Hair vaccine treatments repair extremely damaged hair structure and its effect on the research. Journal of Beauty Industry, 4: 35-42, 2013.

Jeong HL, Kim HW, Kim JH, Kim JH, Kim DU. Cosmetic effect of mixed plant extracts including Saururus Chinensis, Morus Bombycis stem and Morus Papyrifera stem. Korean Chemical Engineering Research, 50: 610-613, 2012.

Jung HH, Shin MK, Lee SY, Lee SR, Kim MS. Effect of extract from fermented black soybean (glycine max var. Seoritae) on the hair damaged by decolorization. Journal of the Society of Cosmetic Scientists of Korea, 43: 149-155, 2017.

Kim JS, Kim CS, Kim YJ, Yoo SE. Hair science. Hoonminsa, Seoul, pp79-80, 2010.

Kim JS. Effect of peanut oil on hair texture improvement. Asian
Journal of Beauty and Cosmetology, 18: 331-340, 2020.

Kim JS. Effects of mink oil on improving hair texture. Journal of the Korean Applied Science and Technology, 37: 12981305, 2020.

Lee HN, Ham MY. Hair damage rates and morphological changes from application of a reducing agent prescribing ginseng extract. Asian Journal of Beauty and Cosmetology, 8: 211-223, 2010.

Lee MK, Cho JH. Physical changes in chemically damaged hair with gookhwasan extract. Journal of the Korean Society of Beauty and Arts, 61: 97-106, 2018.

Lim DJ. Improvement effects of hair texture by using sodium bromate oxidizing agent. The Korean Society of Science \& Art, 35: 391-400, 2018.

Lim HJ, Lee JY, Kim HB, Kim DH, Shin SS. Preparation and evaluation of polymer microspheres containing Broussonetia Kazinoki root extract. Journal of the Society of Cosmetic Scientists of Korea, 39: 89-96, 2013.

Min MJ, Na MS, Ryu EM, Cha WS. Gray mulet extract on physical damage of colored and bleached hair. Asian Journal of Beauty and Cosmetology, 25: 1-9, 2011.

Park GM, Park SY, Kim BK. A study on the effect of polypeptide and water-soluble silicon on hair discoloration. Journal of Health and Beauty, 13: 45-52, 2019.

Park HJ, Kwack SJ. A study on hair damage of permissible hair dye ingredients in Korea. Journal of the Korea Society of Cosmetics and Cosmetology, 8: 379-386, 2018.

Park SA, Ha JH, Park SN. Antioxidative activity and component analysis of Broussonetia kazinoki SIEB extracts. Applied Chemistry for Engineering, 24: 177-183, 2013. 


\section{국문초록}

\section{닥나무 추출물에 의한 손상 모발의 개선효과}

김주섭

상지대학교 뷰티디자인학과, 강원도 원주시, 한국

목적: 본 연구는 닥나무 추출물을 첨가한 모질 개선 제형제를 제조하여 손상된 모발에 도포하여 모발의 질 개선 효과를 알아보고 자 하였다. 방법: 실험방법과 측정은 닥나무 추출물 함량을 $0 \mathrm{~g}, 2 \mathrm{~g} 4 \mathrm{~g}, 6 \mathrm{~g}$ 으로 다르게 하여 제형제를 제조하였다. 제조한 제형제 로 탈색한 시료 모발에 도포 후 열처리와 자연방치를 한 후에 시료 별로 도포 전과 후를 측정하여 비교 분석하였다. 모발의 질 개선 효과를 알기 위해 인장강도, 메틸렌블루를 이용한 흡광도, 광택을 측정하였다. 결과: 인장강도 측정결과는 모든 시료에서 도포 후 에 평균값이 증가하였다. 통계분석 결과로는 $7 \mathrm{~L}(0)$ 를 제외한 $7 \mathrm{~L}(1), 7 \mathrm{~L}(2), 7 \mathrm{~L}(3), 9 \mathrm{~L}(3)$ 의 시료에서 인장강도가 증가하였다. 메틸 렌블루를 이용한 흡광도 분석결과, 건강모를 제외한 시료시료들에서 도포 후 평균값이 감소하였다. 통계분석결과는 $7 \mathrm{~L}(1), 7 \mathrm{~L}(2)$, $7 \mathrm{~L}(3), 9 \mathrm{~L}(3)$ 의 시료에서 감소하는 것을 알 수 있었다. 광택 측정결과는 모든 시료에서 평균값이 증가하였다. 통계분석결과 $7 \mathrm{~L}(3)$, $9 \mathrm{~L}(3)$ 의 시료에서 증가하였다. 결론: 인장강도, 흡광도, 광택 측정 변화로 인해 닥나무 추출물이 손상된 모발에 질 개선 효과가 있는 것을 알 수 있었다. 차후 다양한 측정 방법과 성분 연구가 필요하다.

핵심어: 닥나무, 모발, 개선, 모질, 손상

\section{참고문헌}

김주섭, 김찬수, 김유정, 유세은. 모발과학. 훈민사, 서울, $\mathrm{pp} 79-80,2010$.

김주섭. 밍크오일의 모질 개선효과. 한국응용과학기술학회지, 37: 1298-1305, 2020.

김주섭, 땅콩오일의 모질 개선효과 연구. 아시안뷰티화장품학술지, 18: 331-340, 2020.

민명자, 나명순, 류은님, 차월석. 숭어추출물이 염색과 탈색 모발의 물리적 손상에 미치는 영향. 아시안뷰티화장품학술지,

25: 1-9, 2011.

박가미, 박선이, 김병관. Polypeptide와 수용성 규소가 모발 손상도에 미치는 영향. 국제보건미용학회지, 13: 45-52,

2019

박수아, 하지훈, 박수남. 닥나무 추출물의 항산화 활성 및 성분 분석. 공업화학, 24: 177-183, 2013.

박효정, 곽승준. 국내 허용 염모제 성분의 모발손상도에 한 연구. 한국화장품미용학회지, 8: 379-386.

백해진, 이유라, 전기흥. 닥나무를 이용한 천연비누 개발과 효과 분석에 관한 연구. 한국공예논종, $11: 1-20,2008$.

이민경, 조지훈. 국화산 추출물에 의한 화학적 손상모발의 물리학적 변화. 한국인체미용예술학회지, $61: 97-106,2018$.

이하나, 함미영. 인삼 추출물을 처방한 환원제 적용에 따른 모발 손상도 및 형태학적 변화. 아시안뷰티화장품학술지, 21 :

211-223, 2010.

임대진. 브롬산나트륨 산화제 사용에 의한 모발 개선효과. 한국과학예술융합학회지, 35: 391-400, 2018.

임현준, 이진영, 김한별, 김도훈, 손송석. 닥나무 뿌리 추출물을 함유하는 고분자 마이크로입자 제조 및 평가. 대한화장품

학회지, 39: 89-96, 2013.

정향리, 김현우, 김지혜, 김진홍, 김동욱. 삼백초, 뽕나무 줄기, 닥나무 줄기 등을 함유한 복합수목추출물의 화장품 소재

특성. 화학공학, 50: 610-613, 2012.

정희훈, 신민규. 이수열, 이상린, 김무성. 서리태 발효추출물이 탈색을 통해 손상된 모발에 미치는 영향. 대한화장품학회

지, 43: 149-155, 2017.

차운호. 헤어 백신트리트먼트의 극손상모발 구조 복구 및 그 효능에 관한 연구. 미용산업연구, 4: 35-42, 2013. 


\section{中文摘要}

\section{枸树提取物对受损头发的影响}

金周爕

尚志大学美容学科, 江原道原州市, 韩国

目的：该研究旨在制造添加枸树的配方以改善头发质量，将其应用于受损头发，并检查配方在改善头发质量方面 的效果。方法: 通过改变 0、2、4和 6 g枸树提取物的含量来制备制剂。然后，将制剂应用于脱色的样品毛发， 将其加热处理并留在自然中。然后, 比较了施用制剂之前和之后样品毛发的状况。为了检查配方对头发质量的 影响, 该研究测量了拉伸强度、使用亚甲蓝的光吸收和光泽。结果: 对于所有样品, 应用配方后拉伸强度的平均 值均增加, 作为统计分析的结果, 除了 $7 \mathrm{~L}(0)$ 之外, $7 \mathrm{~L}(1) 、 7 \mathrm{~L}(2) 、 7 \mathrm{~L}(3)$ 和 $9 \mathrm{~L}(3)$ 的样品的拉伸强度增加。使用亚 甲蓝的光吸收分析表明, 除健康头发外, 所有样品的光吸收平均值均下降。统计分析结果, 在 $7 \mathrm{~L}(1) 、 7 \mathrm{~L}(2)$ 、 $7 \mathrm{~L}$ (3)和 $9 \mathrm{~L}$ (3)的样品中减少。最后, 所有样品的光泽度测量平均值均增加。作为统计分析的结果, 它在 $7 \mathrm{~L}(3)$ 和 $9 \mathrm{~L}(3)$ 的样品中增加。结论: 研究发现, 枸树提取物可有效改善受损头发的抗张强度、吸光度和光泽。然而, 该 研究仅验证了有限数量的头发特征的结果, 并使用了一种成分。因此, 需要使用各种测量方法和其他成分进行 进一步研究。

关键词: 枸树, 头发, 改善, 头发质地，损伤 